\title{
Integrative Approach Based on Simplex-Centroid Design, ESI-MS and Chemometric Analysis for Comprehensive Characterization of Phenolic Compounds from Endopleura uchi Bark
}

\author{
Lílian M. Bastos, ${ }^{\oplus *, a, b}$ Felipe M. A. da Silva, ${ }^{\oplus b, c}$ Leonard R. S. de Souza, ${ }^{b}$ Ingrity S. C. Sá, ${ }^{b}$ \\ Rochelly S. Mesquita, ${ }^{b}$ Afonso D. L. de Souza ${ }^{b, c}$ and Rita de Cássia S. Nunomura ${ }^{b, c}$ \\ aPrograma de Pós-Graduação em Inovação Farmacêutica, Universidade Federal do Amazonas, \\ 69077-000 Manaus-AM, Brazil \\ ${ }^{b}$ Central Analítica-Centro de Apoio Multidisciplinar (CAM), Universidade Federal do Amazonas, \\ 69077-000 Manaus-AM, Brazil
}

'Departamento de Química, Universidade Federal do Amazonas, 69077-000 Manaus-AM, Brazil

\begin{abstract}
Endopleura uchi (Huber) Cuatrec. is an Amazonian medicinal plant with restricted distribution to the North Region of Brazil. Its bark is commonly used as natural medicines for the treatment of many diseases. Although widely investigated from the phytochemical viewpoint, the knowledge regarding the phenolic content remains unexplored. In order to access the phenolic composition of E. uchi bark, an integrative approach based on simplex-centroid design, direct infusion electrospray ionization mass spectrometry (ESI-MS) and chemometric analysis was adopted. In addition, the extracts were evaluated to total phenolic content and antioxidant activity. The multivariate analysis pointed to the ethanol-based extracts as the most representative for phenolic compounds, with 3,5-di-O-galloylquinic acid (2), gallic acid (4), 5-galloylquinic acid (5) and gallocatechin gallate (6) tentatively identified by MS analysis, all described for the first time in E. uchi. Besides, pure

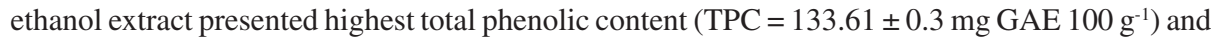
antioxidant activity (half maximal inhibitory concentration, $\mathrm{IC}_{50}=9.32 \pm 0.15$ ). The integrative approach proposed to this work provided an effective way to assess the phenolic compounds of E. uchi bark, therefore, improving the knowledge regarding phenolic content in this Amazonian medicinal plant.
\end{abstract}

Keywords: DPPH, galloylquinic acid derivatives, HCA, PCA, total phenolic content

\section{Introduction}

Endopleura uchi (Huber) Cuatrec. (Humiriaceae), popularly known as "uxi-amarelo" or "uxi-liso", is a native tree of the Brazilian Amazon rainforest found throughout the Amazon basin. ${ }^{1}$ Its bark is commonly marketed in popular fairs and pharmacies, being prescribed in the form of tea for the treatments of diabetes, fibroids, and cysts, and as anti-inflammatory. ${ }^{2}$ Phytochemical studies performed with $E$. uchi pointed bergenin as the major constituent, while the knowledge regarding the phenolic content remains almost unexplored ${ }^{3-5}$ Research on phenolic compounds has been a focus of interest in the last decade due to several beneficial effects in human health. ${ }^{6}$

*e-mail: lilianbastos3@hotmail.com
Direct infusion electrospray ionization mass spectrometry (ESI-MS) analysis has been used as an efficient fingerprinting method for rapid detection of bioactive compounds in a complex matrix. ${ }^{7,8}$ This approach has been successfully applied to the tentative identification of phenolic compounds in several plant species, food, and other products. ${ }^{9}{ }^{10}$ Mass spectrometry-based approaches in combination with statistical mixture designs (e.g., simplexcentroid design) and unsupervised analysis (e.g., principal component analysis and hierarchical cluster analysis) have allowed the identification of synergistic and antagonistic interactions between different extraction solvents, maximizing or minimizing the contents of extracted compounds, and highlighting target compounds. ${ }^{8,11,12}$

In this work, bark extracts of E. uchi were obtained with dichloromethane, ethyl acetate and ethanol in different combinations, according to simplex-centroid design, and 
analyzed by direct infusion ESI-MS, being these data subjected to hierarchical cluster analysis (HCA) and principal component analysis (PCA) analysis in order to access the phenolic composition of $E$. uchi bark. In addition, the extracts were evaluated to total phenolic content and antioxidant activity.

\section{Experimental}

\section{Chemicals}

Standards including gallic acid, quercetin, FolinCiocalteau reagents and 2,2-diphenyl-1-picrylhydrazyl hydrate (DPPH) were purchased from Sigma-Aldrich (St. Louis, MO, USA). Methanol, dichloromethane, ethyl acetate, and ethanol were high performance liquid chromatography (HPLC) grade purchased from Tedia (Fairfield, OH, USA), and the water was purified by using a Milli-Q system (Millipore, Bedford, MA, USA).

\section{Plant material}

The bark of E. uchi was collected in February 2016 at the Adolpho Ducke Forest Reserve $(26 \mathrm{~km}$ along the AM-010 highway, at Manaus city, Amazonas state,

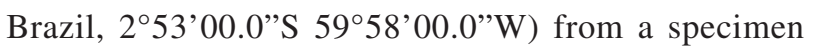
previously identified and cataloged during the Flora Project. ${ }^{13}$ The access to genetic heritage was registered at Sistema Nacional de Gestão do Patrimônio Genético e do Conhecimento Tradicional Associado (SisGen) under the code No. A7C1655. A voucher (No. 177673) was deposited in the herbarium of the Instituto Nacional de Pesquisas da Amazônia (INPA).

\section{Extraction procedures}

The plant bark was dried over $40{ }^{\circ} \mathrm{C}$ in the air circulating during $24 \mathrm{~h}$, and then powdered. Extractions were performed with approximately $5 \mathrm{~g}$ of dried material, which was macerated in $30 \mathrm{~mL}$ of pure solvent or a mixture of solvents (dichloromethane (dc), ethyl acetate (ea) and ethanol (et)) in different proportions according to a simplexcentroid design (Figure 1). ${ }^{14}$ The extraction procedures were performed in an ultrasonic bath for $15 \mathrm{~min}$ at constant temperature $\left(31^{\circ} \mathrm{C}\right)$. The extracts were filtered through filter paper and the solvent evaporated to dryness under a nitrogen gas stream to yield seven crude extracts (Table 1).

\section{Mass spectrometry analysis}

Stock solutions $\left(1 \mathrm{mg} \mathrm{mL}^{-1}\right)$ of the bark extracts were

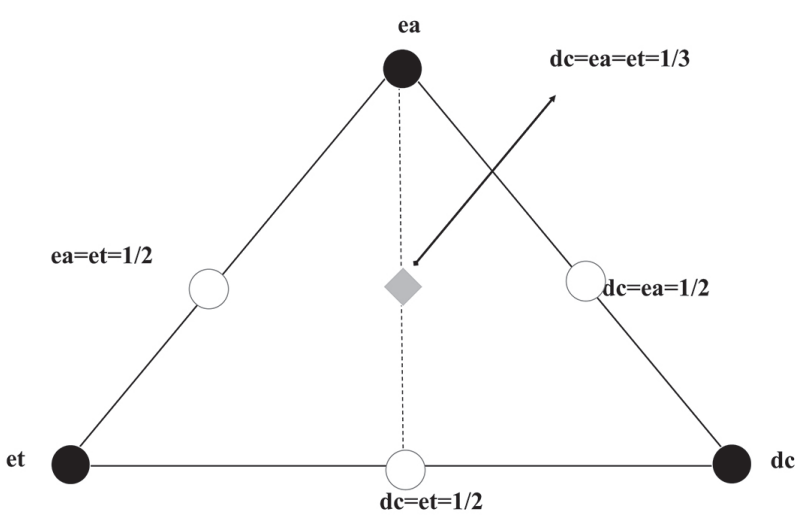

Figure 1. The simplex-centroid design prepared using mixtures of three components dichloromethane (dc), ethyl acetate (ea) and ethanol (et).

prepared with methanol. Aliquots $(5 \mu \mathrm{L})$ of the stock solutions were further diluted to $5 \mu \mathrm{g} \mathrm{mL} \mathrm{m}^{-1}$ and analyzed by direct infusion into the mass spectrometers. A LCQ Fleet ion-trap mass spectrometer with electrospray ionization (ESI) interface and running in the negative ion mode was used to perform ESI-MS and a TSQ Quantum Access mass spectrometer to perform ESI-MS/MS analyses. Samples were directly infused into the ion source through the instrument syringe pump $\left(10 \mu \mathrm{L} \mathrm{min}{ }^{-1}\right)$. MS analytical conditions: spray voltage, $5 \mathrm{kV}$; sheath gas, 10 arbitrary unit (arb); auxiliary gas, 5 arb; sweep gas, 0 arb; capillary temp, $200^{\circ} \mathrm{C}$; capillary voltage, $40 \mathrm{~V}$; tube lens, $115 \mathrm{~V}$; mass range, $\mathrm{m} / z 100$ to 600 . Argon was used as collision gas, and the ESI-MS/MS spectra were obtained using collision energies ranging from 30 to $35 \mathrm{eV} .^{8}$

\section{Chemometric analysis}

Multivariate analysis was performed through the software Chemoface, version $1.5 .^{15}$ Ions with intensity below $5 \%$ relative to the base peak at each mass spectrum were neglected during data analysis. ${ }^{8}$

\section{Total phenolic content (TPC)}

The total phenolic content in each extract was determined in a 96-well microplate using Folin-Ciocalteu reagents according to a previously described method with some modifications. ${ }^{16}$ Briefly, $20 \mu \mathrm{L}$ of each extract solution at $1 \mathrm{mg} \mathrm{mL}^{-1}$ was mixed with $150 \mu \mathrm{L}$ of Folin-Ciocalteu reagent (previously diluted 10 -fold with distilled water). After $5 \mathrm{~min}, 150 \mu \mathrm{L}$ of $6 \%$ sodium bicarbonate solution was added to the mixture and allowed to stand for $90 \mathrm{~min}$ at room temperature in the dark. The absorbance of the mixture was measured at $750 \mathrm{~nm}$ with an ELX 808 Reader (Biotek, Burlington, VT). A calibration curve was prepared using a standard solution of gallic acid and the total 
phenolic content was expressed in mg gallic acid equivalent (GAE) per $100 \mathrm{~g}$ of extract.

\section{Antioxidant activity using DPPH}

DPPH free radical scavenging activity was measured according to the method previously described with some modifications. ${ }^{16}$ Briefly, $30 \mu \mathrm{L}$ of each extract solution in various concentrations (500-7.8 $\left.\mu \mathrm{g} \mathrm{mL}^{-1}\right)$ was mixed with $270 \mu \mathrm{L}$ of DPPH $(100 \mu \mathrm{M})$ and allowed to stand for $30 \mathrm{~min}$ at room temperature in the dark. The absorbance of the mixture was measured at $515 \mathrm{~nm}$ with an ELX 808 Reader (Biotek, Burlington, VT). A calibration curve was prepared using a standard solutions of quercetin (100-1.56 $\left.\mu \mathrm{g} \mathrm{mL}^{-1}\right)$.

\section{Results and Discussion}

The phenolic content of Endopleura uchi bark was tentatively extracted by 7 different extractor solutions using pure or mixtures of three components: dichloromethane (dc), ethyl acetate (ea) and ethanol (et). The criterion of choice was based on different characteristics of solvents. ${ }^{17}$ Table 1 shows the effects of the solvent compositions on the yield of crude extract. The highest yield was observed to the pure ethanol (et) (43.1\%) and mixture of ethanol and ethyl acetate (et + ea) (13.2\%), while the lowest yield was obtained from the combination of dichloromethane and ethyl acetate $(\mathrm{ea}+\mathrm{dc})(0.2 \%)$, and pure dichloromethane (dc) $(0.5 \%)$. Regarding to total phenolic, et extract presented highest content $(\mathrm{TPC}=133.61 \pm 0.3 \mathrm{mg}$ GAE per $100 \mathrm{~g})$, presenting also high DPPH free radical scavenging activity (half maximal inhibitory concentration, $\mathrm{IC}_{50}=9.32 \pm 0.15$ ). These observations are in agreement with previously reported studies ${ }^{4,5}$ with bark extracts of E. uchi that highlighted the influence of extractive processes over the characteristics of the extracts and pointed the ethanol- based extracts as promising to phenolic compounds and antioxidant activity.

The fingerprint direct infusion negative ESI mass spectrum of the bark extracts from $\mathrm{m} / \mathrm{z} 100$ to 600 (Figure 2) displayed deprotonated base peak at $m / z, 191$ for dc, $m / z 327$ for ea and ea $+\mathrm{dc}$, and $\mathrm{m} / \mathrm{z}, 495$ for the ethanol-based extracts (Figure 2). Besides base peak, several other ions were observed, suggesting these samples as a complex matrix.

Analysis of the MS spectra revealed that 96 ions remained after the elimination of the 5\% least intense ions (Table S1, Supplementary Information (SI) section). Therefore, PCA was calculated through the variation of these ions, being HCA calculated through the Euclidian distances and average linkage of the first four principal components, whose cumulative variance represents 98.55\%. In the PCA score plot (Figure 3a) three main groups (group I-III) were observed, highlighting the presence of ethanol-based extracts at group III, being this constituted by the highest yield extracts (et and et + ea). The HCA dendrogram (Figure 3b) clearly confirmed the same four groups from the PCA analysis and suggested that ethanol-based extracts present lower chemical variability than nonpolar based extracts.

According to the PCA biplot (Figure 3c), the ions at $\mathrm{m} / \mathrm{z} 191,327$ and 495 were the main responsible for the segregation of the groups I-III. Through the MS/MS spectra of these ions (Figures S9 to S12, SI section), we could observe key fragmentations previously described for phenolic compounds. The main observed fragmentations were summarized in Table 2 . The deprotonated ion at $\mathrm{m} / \mathrm{z} 191$ displayed two main fragments at $\mathrm{m} / \mathrm{z}, 93$ and 85, consistent with the structure of quinic acid (1) (Figure 4), ${ }^{18}$ while the ion at $m / z, 495$ presented fragments at $m / z, 343$, 325,191 and 169, the last two corresponding to quinic and gallic acid moiety, respectively. Based on the relative abundance of these ions, this fragmentation is consistent

Table 1. The yield of crude extracts obtained by different extractor solutions using pure or mixtures of solvents and total phenolic content

\begin{tabular}{|c|c|c|c|c|c|c|}
\hline \multirow{2}{*}{ Extract } & \multicolumn{3}{|c|}{ Solvent / $(\%, \mathrm{v} / \mathrm{v})$} & \multirow{2}{*}{ Yield $/(\%, \mathrm{~m} / \mathrm{m})^{\mathrm{d}}$} & \multirow{2}{*}{$\begin{array}{c}\text { Total phenolic content / } \\
\text { (mg GAE } \text { per } 100 \mathrm{~g} \text { of extract) }\end{array}$} & \multirow{2}{*}{$\begin{array}{c}\mathrm{DPPH} \\
\mathrm{IC}_{50}^{\mathrm{f}, \mathrm{g}} /\left(\mu \mathrm{g} \mathrm{mL} \mathrm{mL}^{-1}\right)\end{array}$} \\
\hline & $\mathrm{dc}^{\mathrm{a}}$ & $\mathrm{ea}^{\mathrm{b}}$ & $\mathrm{et}^{\mathrm{c}}$ & & & \\
\hline 1 & 100 & 0 & 0 & 0.5 & $35.66 \pm 0.02$ & $195.4 \pm 0.02$ \\
\hline 2 & 0 & 100 & 0 & 3.3 & $74.93 \pm 0.07$ & $29.10 \pm 0.11$ \\
\hline 3 & 0 & 0 & 100 & 43.1 & $133.61 \pm 0.3$ & $9.32 \pm 0.15$ \\
\hline 4 & 50 & 50 & 0 & 0.2 & $52.94 \pm 0.08$ & $215.22 \pm 0.07$ \\
\hline 5 & 50 & 0 & 50 & 5.3 & $81.66 \pm 0.03$ & $43.08 \pm 0.14$ \\
\hline 6 & 0 & 50 & 50 & 13.2 & $71.16 \pm 0.01$ & $30.36 \pm 0.16$ \\
\hline 7 & 33.3 & 33.3 & 33.3 & 5.9 & $23.03 \pm 0.02$ & $50.42 \pm 0.17$ \\
\hline
\end{tabular}

${ }^{\mathrm{a} D i c h l o r o m e t h a n e ; ~}{ }^{\mathrm{b}}$ ethyl acetate; ${ }^{\mathrm{c} e t h a n o l ;}{ }^{\mathrm{d}}$ relative to dried bark material; ${ }^{\mathrm{e}} \mathrm{GAE}$ : gallic acid equivalent; ${ }^{\mathrm{f}} \mathrm{DPPH}$ : 2,2-diphenyl-1-picrylhydrazyl hydrate free radical scavenging activity; ${ }^{\mathrm{g}}$ standard reference (quercetin, $\mathrm{IC}_{50}=4.07 \pm 0.04 \mu \mathrm{g} \mathrm{mL}^{-1}$ ). 


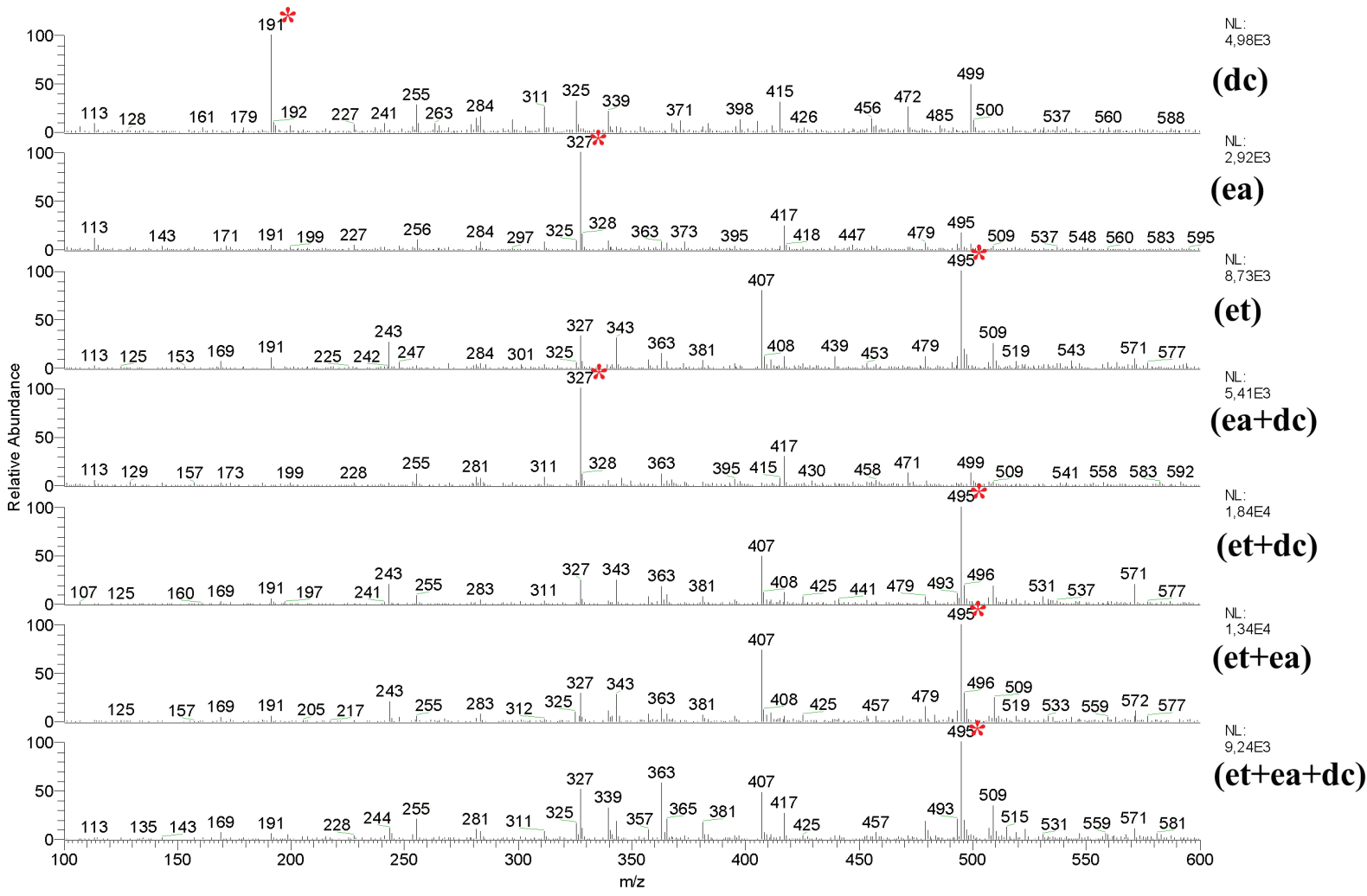

Figure 2. Total ion spectra of the extracts from E. uchi bark with * denoting the base peak.

(a)
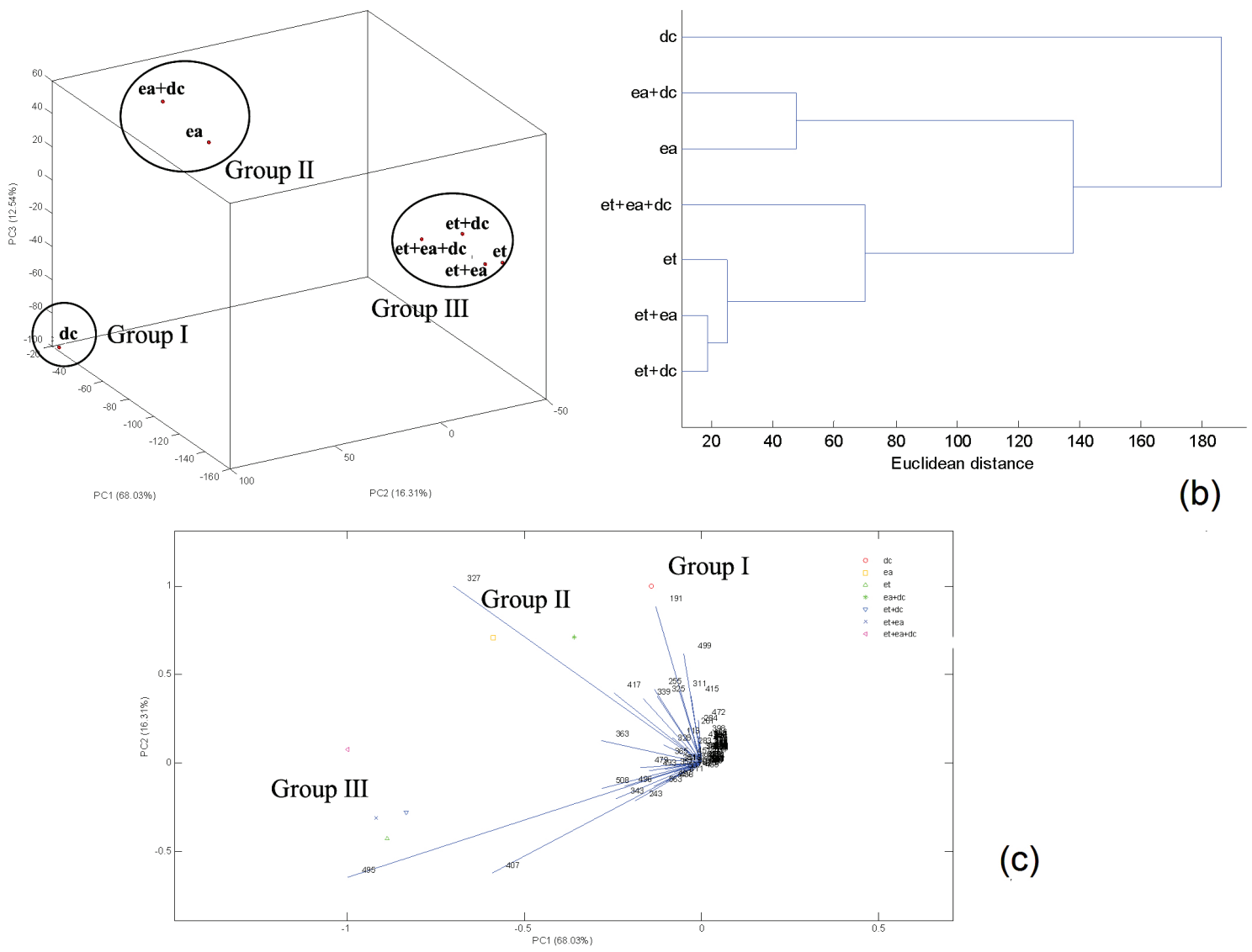

(c)

Figure 3. PCA score plot (a), HCA dendrogram (b) and PCA biplots (c). 
<smiles>O=C(O)C1(O)CC(O)C(O)C(O)C1</smiles>

(1) quinic acid<smiles>O=C(O)c1cc(O)c(O)c(O)c1</smiles>

(4) galic acid<smiles>O=C(OC1CC(O)(C(=O)O)CC(OC(=O)c2cc(O)c(O)c(O)c2)C1O)c1cc(O)c(O)c(O)c1</smiles>

(2) 3,5-di-O-galloylquinic acid<smiles>COc1c(O)cc2c(c1O)C1OC(CO)C(O)C(O)C1OC2=O</smiles>

(3) bergenin<smiles>O=C(OC1CC(O)(C(=O)O)CC(O)C1O)c1cc(O)c(O)c(O)c1</smiles>

(5) 5-galloylquinic acid<smiles>[14CH3]OC(=O)c1cc(O)c(O)c(O)c1</smiles>

Figure 4. Tentatively identified compounds from the E. uchi bark.

with the structure of 3,5-di- $O$-galloylquinic acid (2). ${ }^{19}$ The MS/MS spectra of the deprotonated ions at $\mathrm{m} / z 327$ present fragments at $\mathrm{m} / \mathrm{z} 312,249$, and 207, being these key fragments previously reported to the bergenin (3), a $\mathrm{C}$-glucoside of 4-O-methyl gallic acid. ${ }^{20}$ Therefore, the multivariate analysis pointed to 3,5-di- $O$-galloylquinic acid (2) as important components in the ethanol-based extracts, while bergenin (3) was observed mainly in the pure ethyl acetate and mixture with dichorometane. In addition, quinic acid (1) was highlighted in the pure dichorometane extract.

Other ions at $\mathrm{m} / \mathrm{z} 169,343$ and 457, present in ethanol-based extracts, were tentatively identified by the fragmentation experiments (Figures S8 to S13 from SI section). The MS/MS spectra of the deprotonated ion at $\mathrm{m} / \mathrm{z} 169$ presented the main fragment at $\mathrm{m} / \mathrm{z} 125$, being this consistent with the structure of the gallic acid (4).${ }^{18}$ For the ion at $m / z 343$ the MS/MS spectra presented the base peak at $m / z 191$, and a less intense ion at $m / z 169$, corresponding to quinic and gallic acid moiety, respectively. Although these ions are common for galloylquinic acid isomers, the base peak at $\mathrm{m} / \mathrm{z} 191$ is only reported to 5-galloylquinic acid (5), which is in accordance with the substitution pattern proposed for 3,5-di-O-galloylquinic acid (2). ${ }^{19}$ In the MS/MS spectra of the ion at $m / z 457$ were observed several fragment ions highlighting an intense product ion at $m / z 169$ and a minor ion at $\mathrm{m} / \mathrm{z} 305$, corresponds to gallic acid and gallocatechin units, respectively. This fragmentation pathway is consistent with the structure of the gallocatechin gallate $(\mathbf{6}) .^{21}$
Table 2. Compounds tentatively identified in the Endopleura uchi bark by ESI-MS/MS experiments

\begin{tabular}{lcc}
\hline Compound & {$[\mathrm{M}-\mathrm{H}]^{-}$} & MS/MS \\
\hline Quinic acid (1) & 191 & 93,85 \\
3,5-di-O-Galloylquinic acid (2) & 495 & $343,325,191,169$ \\
Bergenin (3) & 327 & $312.249,207$ \\
Gallic acid (4) & 169 & 125 \\
5-Galloylquinic acid (5) & 343 & 191,169 \\
Gallocatechin gallate (6) & 457 & 305,169 \\
\hline
\end{tabular}

\section{Conclusions}

The integrative approach based on simplex-centroid design, direct infusion ESI-MS, and chemometric analysis provided a simple and useful strategy to assess the phenolic compounds of E. uchi bark, therefore improving the knowledge regarding the chemical composition of this Amazonian medicinal plant. The ethanol-based extracts were highlighted as the most representative for phenolic compounds, with 3,5-di- $O$-galloylquinic acid, gallic acid, 5-galloylquinic acid and gallocatechin gallate described for the first time in this species.

\section{Supplementary Information}

Supplementary information (Figures S1-S13, Table S1) is available free of charge at http://jbcs.sbq.org.br as PDF file. 


\section{Acknowledgments}

The authors are grateful to Central Analítica (UFAM) for MS analysis, and CNPQ, FINEP and FAPEAM for financial support.

\section{References}

1. http://floradobrasil.jbrj.gov.br/reflora/floradobrasil/FB23295 accessed in January 2019.

2. Corrêa, M. P.; Dicionário das Plantas Úteis do Brasil e das Exóticas Cultivadas; Imprensa Nacional: Rio de Janeiro, 1984.

3. Nunomura, R. C. S.; Oliveira, V. G.; Silva, S. L.; Nunomura, S. M.; J. Braz. Chem. Soc. 2009, 20, 1060.

4. Tacon, L. A.; Freitas, L. A. P.; Rev. Bras. Farmacogn. 2013, 23, 65 .

5. Silva, L. R.; Teixeira, R.; Asian Pac. J. Trop. Med. 2015, 8, 889.

6. Lin, D.; Xiao, M.; Zhao, J.; Li, Z.; Xing, B.; Li, X.; Kong, M.; Li, L.; Zhang, Q.; Liu, Y.; Chen, H.; Qin, W.; Wu, H.; Chen, S.; Molecules 2016, 21, 1374.

7. Schiozer, A. L.; Cabral, E. C.; Godoy, L. A. F.; Chaves, F. C. M.; Poppi, R. J.; Riveros, J. M.; Eberlin, M. N.; Barata, L. E. S.; J. Braz. Chem. Soc. 2012, 23, 409.

8. Silva, F. M. A.; Silva-Filho, F. A.; Lima, B. R.; Almeida, R. A.; Soares, E. R.; Koolen, H. H. F.; Souza, A. D. L.; Pinheiro, M. L. B.; J. Braz. Chem. Soc. 2016, 27, 599.

9. Pereira, V. V.; Fonseca, F. A.; Bento, C. S. O.; Oliveira, P. M.; Rocha, L. L.; Augusti, R.; Mendonça-Filho, C. V.; Silva, R. R.; Rev. Virtual Quim. 2015, 7, 2539.

10. Moller, J. K. S.; Catharino, R. R.; Eberlin, M. N.; Analyst 2005, 130,890 .
11. Pauli, E. D.; Scarminio, I. S.; Tauler, R.; J. Chemom. 2016, 30, 75.

12. Rocha, P. R. N.; Freitas, F. A.; Angolini, C. F. F.; Vasconcelos, L. S. F.; Silva, A. L. B.; Costa, E. V.; Silva, F. M. A.; Eberlin, M. N.; Bataglion, G. A.; Soares, P. K.; Koolen, H. H. F.; Phytochem Anal. 2018, 29, 569.

13. Ribeiro, J. E. L. S.; Hopkins, M. J. G.; Vicentini, A.; Sothers, C. A.; Costa, M. A. S.; Brito, J. M.; Souza, M. A. D.; Martins, L. H. P.; Lohmann, L. G.; Assunção, P. A. C. L.; Pereira, E. C.; Silva, C. F.; Mesquita, M. R.; Procópio, L. C.; Flora da Reserva Ducke: Guia de Identificação das Plantas Vasculares de uma Floresta de Terra Firme na Amazônia Central; INPA: Manaus, 1999.

14. Soares, P. K.; Scarminio, I. S.; Phytochem. Anal. 2008, $19,78$.

15. Nunes, C. A.; Freitas, M. P.; Pinheiro, A. C. M.; Bastos, S. C.; J. Braz. Chem. Soc. 2012, 23, 2003.

16. Jing, L.; Ma, H.; Pengcheng, F.; Gao, R.; Jia, Z.; BMC Complementary Altern. Med. 2015, 15, 287.

17. Snyder, L. R.; J. Chromatogr. Sci. 1978, 16, 223.

18. Bataglion, G. A.; Silva, F. M. A.; Eberlin, M. N.; Koolen, H. H. F.; Food Chem. 2015, 180, 280.

19. Clifford, M. N.; Stoupi, S.; Kuhnert, N.; J. Agric. Food Chem. 2007, 55, 2797.

20. Li, B. H.; Wu, J. D.; Li, X. L.; J. Pharm. Anal. 2013, 3, 229.

21. Del-Rio, D.; Stewart, A. J.; Mullen, W.; Burns, J.; Lean, M. E.; Brighenti, F.; Crozier, A.; J. Agric. Food Chem. 2004, 52, 2807.

Submitted: April 4, 2019

Published online: August 7, 2019 